\title{
Laparoscopy for extraperitoneal rectal cancer reduces short-term morbidity: Results of a systematic review and meta-analysis
}

United European Gastroenterology Journal 1(1) $32-47$

(C) Author(s) 2013

Reprints and permissions: sagepub.co.uk/journalsPermissions.nav DOI: $10.1177 / 2050640612473753$ ueg.sagepub.com

@SAGE

\author{
Alberto Arezzo ${ }^{1}$, Roberto Passera ${ }^{2}$, Gitana Scozzari ${ }^{1}$, Mauro Verra ${ }^{1}$ and \\ Mario Morino ${ }^{1}$
}

\begin{abstract}
Background: The role of laparoscopy in the treatment of extraperitoneal rectal cancer is still controversial. The aim of the study was to evaluate differences in safety of laparoscopic rectal resection for extraperitoneal cancer, compared with open surgery.

Materials and methods: A systematic review from 2000 to July 2012 was performed searching the MEDLINE and EMBASE databases (PROSPERO registration number CRD42012002406). We included randomized and prospective controlled clinical studies comparing laparoscopic and open resection for rectal cancer. Primary endpoints were 30-day mortality and morbidity. Then a meta-analysis was conducted by a fixed-effect model, performing a sensitivity analysis by a random-effect model. Relative risk (RR) was used as an indicator of treatment effect.

Results: Eleven studies, representing 1684 patients, met the inclusion criteria: four were randomized for a total of 814 patients. Mortality was observed in $1.2 \%$ of patients in the laparoscopic group and in $2.3 \%$ of patients in the open group, with an RR of $0.56(95 \% \mathrm{Cl} 0.19-1.64, p=0.287)$. The overall incidence of short-term complications was lower in the laparoscopic group (31.5\%) compared to the open group (38.2\%), with an RR of 0.83 (95\% Cl 0.73-0.94, $p=0.004)$. Surgical complications, wound complications, blood loss and the need for blood transfusion, time for bowel movement recovery, food intake recovery, and hospital stay were significantly lower or less frequent in the laparoscopic group. The incidence of intraoperative injuries, anastomotic leakages, and surgical re-interventions was similar in the two groups. Only operative time was in favour of the open group.

Conclusions: Based on the evidence of both randomized and prospective controlled series, mortality was lower after laparoscopy although not significantly so, while the short-term morbidity RR, including subgroup analysis, was significantly lower after laparoscopy for extraperitoneal rectal cancer compared to open surgery.
\end{abstract}

\section{Keywords}

Laparoscopy, meta-analysis, rectal cancer, rectal neoplasms, systematic review

Received: 30 October 2012; accepted: 12 December 2012

\section{Introduction}

Laparoscopy for colon cancer, first described by Jacobs et al. in 1991, ${ }^{1}$ aroused interest after the publication of the randomized trial by Lacy et al. in $2002^{2}$ and obtained acceptance after the publication of the three trials COST, COLOR and CLASICC. ${ }^{3-5}$ With the exception of the CLASICC trial, patients with rectal cancer were not included in these studies.

Excellence of surgical technique is of particular relevance in the treatment of rectal cancer. Routine excision of the intact mesorectum during resection of cancers of the middle and lower rectum has resulted in a consistent reduction of local recurrences ${ }^{6}$ and in an increase in long-term survival rates. ${ }^{7}$

While awaiting long-term oncological results, different studies have reported on postoperative and shortterm results, advocating similar advantages of minimally invasive treatment as for many other procedures,

\footnotetext{
${ }^{1}$ Department of Surgical Sciences, University of Turin, Turin, Italy

${ }^{2}$ Division of Nuclear Medicine, University of Turin, Turin, Italy

Corresponding author:

Alberto Arezzo, Department of Surgical Sciences, University of Turin, corso Dogliotti 14, 10126 Turin, Italy.

Email: alberto.arezzo@unito.it
} 
including less pain, shorter postoperative ileus, earlier return to oral intake, shorter hospital stay, and lower blood loss. ${ }^{89}$ As the analysis of short-term benefits of laparoscopy should be in some way a prerequisite for the analysis of long-term results, with the present study we intended to evaluate in a meta-analysis whether there are clinically relevant short-term advantages of either laparoscopy or laparotomy for surgical treatment of extraperitoneal rectal cancer in the published literature. While the assessment of laparoscopic advantages in rectal cancer treatment has been the topic of other systematic reviews and meta-analyses in the past, this is the first meta-analysis that specifically focuses on extraperitoneal rectal cancer.

\section{Materials and methods}

The methods for the analysis and generation of inclusion criteria were based on the recommendations of the Preferred Reporting Items for Systematic reviews and Meta-Analysis (PRISMA) Statement. ${ }^{10}$ According to population, interventions, comparators, outcome measures, and setting (PICOS) criteria, patients were included if affected with extraperitoneal rectal cancer for which laparoscopic or laparotomic treatment was indicated. The study methods were documented Prospero, an international prospective register of systematic reviews (registration number CRD42012 002406).

\section{Studies}

Only randomized controlled trials (RCTs) or prospective controlled clinical trials (noRCTs) were considered for this analysis, as suggested by the MOOSE group. ${ }^{11}$ Studies were excluded if the study population included colon cancers or intraperitoneal rectal cancers, unless the data were presented separately. When multiple studies from the same institution were identified, the most recent or the most informative was selected. All and only full-text papers in English were considered.

\section{Participants}

This meta-analysis compares laparoscopic and laparotomic resection for extraperitoneal rectal cancer with regard to possible benefits of laparoscopy or laparotomy in the short-term postoperative period, defined as up to 30 days after surgery.

\section{Intervention}

All surgical procedures involving resection of rectal cancers defined either as of the mid and low rectum, or extraperitoneal or lower than $12 \mathrm{~cm}$ from the anal verge, were considered, including partial or total mesorectal excision with mechanical of hand-sutured anastomosis, Hartmann procedures, and abdominoperineal resection. Type of interventions performed were noted in order to analyse separately those involving and those not involving a bowel anastomosis. For the laparoscopic group, any rectal resection performed by means of a mini-invasive approach (i.e. in a space generated by an insufflated pneumoperitoneum with operative field visualization obtained by a videolaparoscope and performed only with laparoscopic trocars) was included, while all procedures described as 'open' or 'conventional' and performed by means of an abdominal laparotomic incision were considered as open surgery.

\section{Outcome measures}

Primary endpoints were overall mortality and morbidity at 30 days after surgery. Intraoperative and early ( $<30$ days) postoperative complications directly related to surgery, and early ( $<30$ days) postoperative medical complications were the subject of different sensitivity analyses. Anastomotic leakage, bleeding and blood loss, wound infection and/or wound dehiscence, pelvic and/or abdominal abscesses, and bowel and/or vascular and/or urological injuries were classified as surgical complications. Paralitic ileum and/or non-surgical bowel obstruction, respiratory events, cardiovascular events, deep venous thrombosis and/or pulmonary embolism, urinary infection, urinary retention, nonsurgical infections, or sepsis were classified as medical complications.

The secondary outcome measures were incidence of anastomotic leakage, abscesses, blood loss, time to first bowel movement, time for intake recovery, need for transfusion, length of hospital stay, wound infections, internal organ injuries, need for re-intervention, and operative time.

\section{Results \\ Study selection}

The search retrieved 5017 studies. Figure 1 illustrates the PRISMA flowchart for study inclusion and exclusion criteria.

\section{Characteristics of included studies}

The characteristics of the 11 studies meeting the inclusion criteria are summarized in Table 1. ${ }^{12-22}$ All 11 studies were reported as full papers and included a total of 1684 patients. Four studies were RCTs for a total of 814 patients and seven studies were noRCTs for a total of 870 patients. 


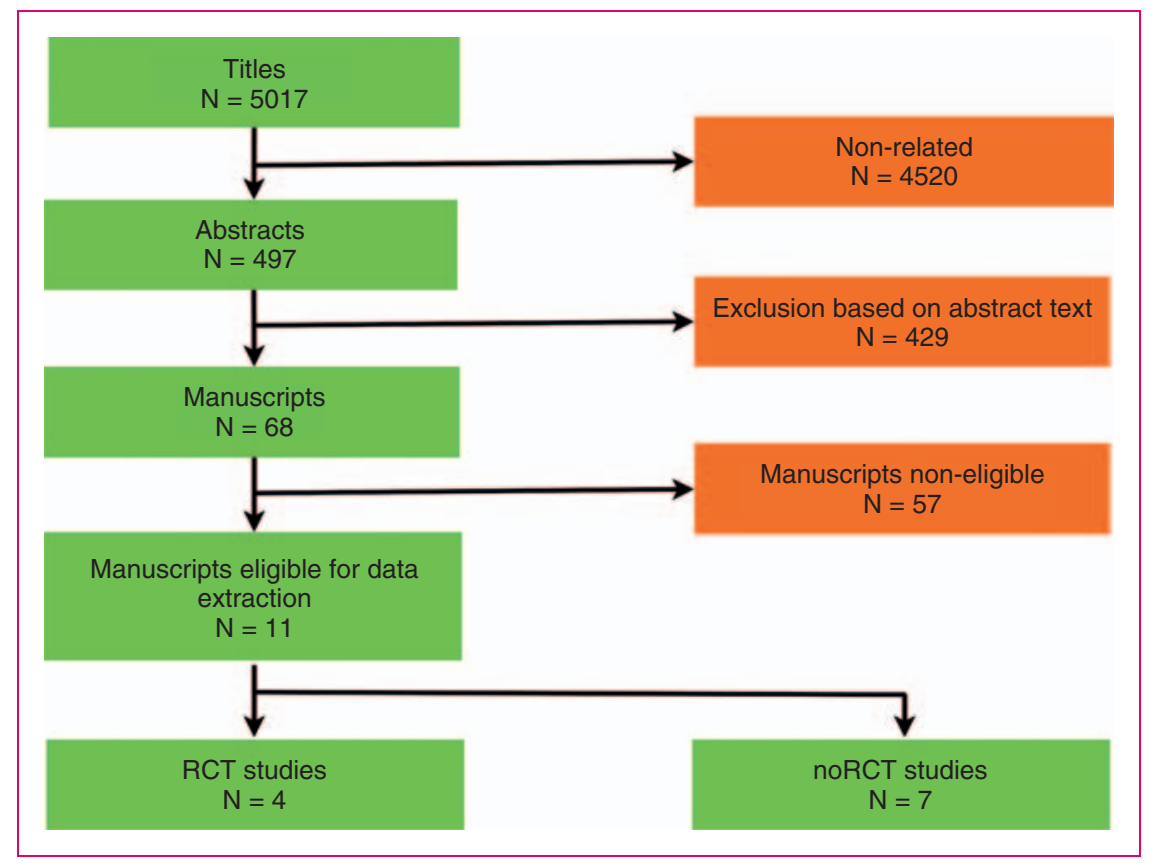

Figure 1. Flow-chart diagram detailing the paper selection process.

Table 2 shows the patients' baseline characteristics comparing open and laparoscopic procedures. Table 3 shows characteristics of tumour location and stage, adjuvant therapy, and percentage of protective ileostomy.

\section{Risk of bias of included studies}

Assessment of quality according to the Cochrane Collaboration's tool for assessing risk of bias for RCTs and to the Newcastle-Ottawa Scale for prospective noRCTs are represented in Tables 4 and 5, respectively.

\section{Quality analysis}

Figure 2 shows the potential sources of heterogeneity within all studies by a L'Abbé plot on mortality outcome. Since in most of the analyses $I^{2}$ was $<50 \%$, the fixed-effects and random-effects model results can be considered comparable.

\section{Primary outcomes}

The meta-analyses of the two primary outcomes investigated mortality and overall complications. For the first primary outcome, the raw incidence of mortality, as reported in five studies, was lower in the laparoscopic group $(1.2 \%)$ compared to the open group $(2.3 \%)$. The overall relative risk (RR) was $0.56(95 \%$ CI $0.19-1.64, p=0.287)$, showing no heterogeneity
$\left(I^{2}=0 \%\right)$ and no differences between RCTs vs. noRCTs subgroups (RR 0.75 vs. $0.41, p=0.590$; Figure 3). Performing a cumulative meta-analysis with these five studies (two RCTs and three noRCTs), adding one study at a time by publication date, the RR progressively raised from 0.33 to 0.59 ; performing an influential meta-analysis, by omitting one study in turn, the RR ranged from 0.50 to 0.60 over the whole time frame.

For the second primary outcome, the incidence of overall 30-day morbidity, as reported in 10 studies, was significantly lower in the laparoscopic (31.5\%) compared to the open group $(38.2 \%)$. The overall RR was $0.83(95 \%$ CI $0.73-0.94, p=0.004)$, showing very low heterogeneity $\left(I^{2}=8.2 \%\right)$ and no statistically significant differences between RCT vs. noRCT trials (RR 0.84 vs. $0.83, p=0.934$; Figure 4 ). Performing a cumulative meta-analysis with these 10 studies (four RCTs and six noRCTs), the RR varied from 0.96 to 0.70 , being almost constant in the period 2007-2011. In the influential meta-analysis, the RR resulted almost stable over the whole publication period, ranging between 0.81 and 0.86 .

\section{Secondary outcomes}

As secondary outcomes, the meta-analysis investigated medical and surgical complications in detail, i.e. patients with medical and/or surgical complications, surgical duration, mean blood loss, incidence of intraoperative injuries, bowel movement recovery, food 


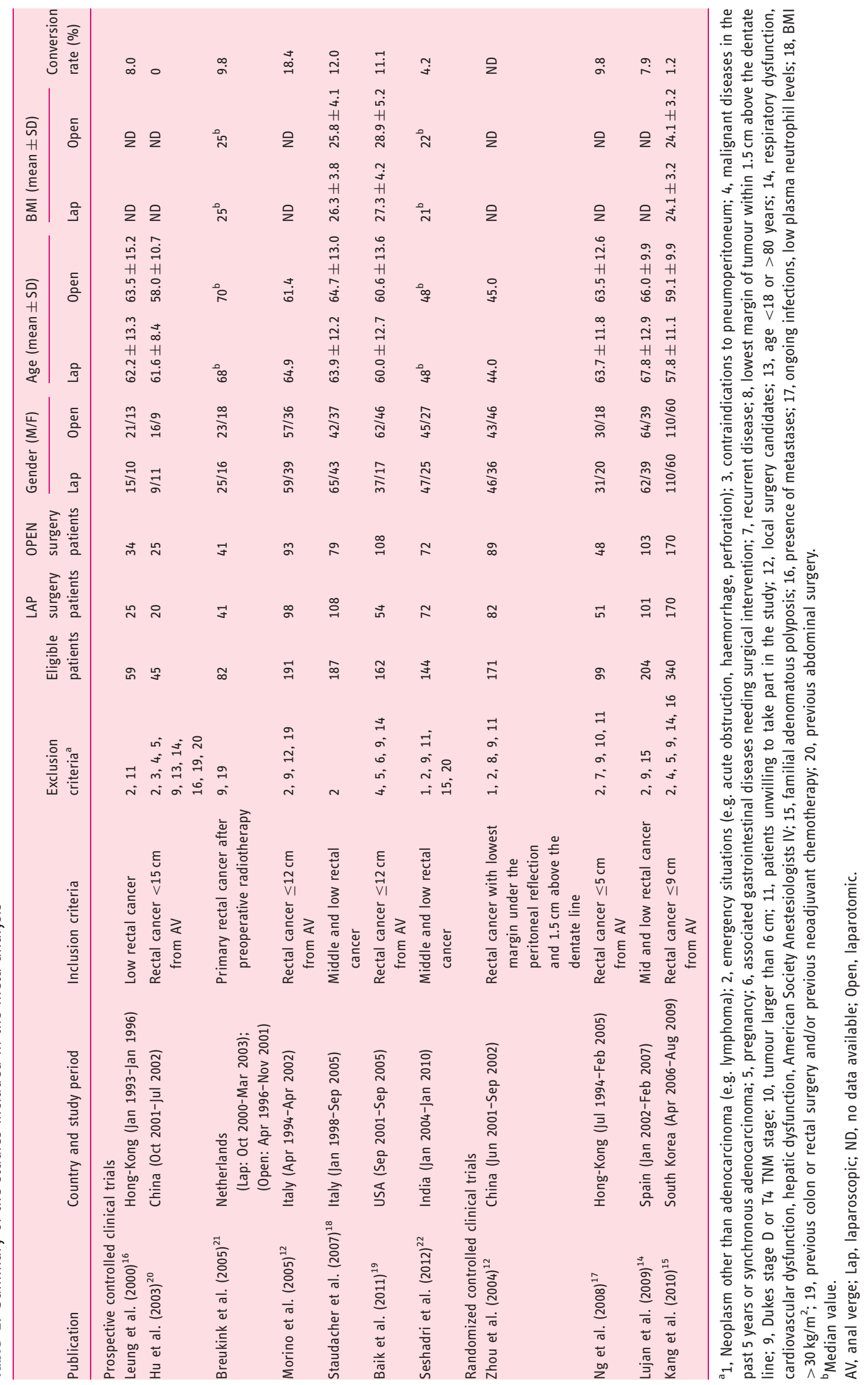


Table 2. Comparison of baseline patient characteristics

\begin{tabular}{|c|c|c|c|c|c|c|c|c|}
\hline & \multicolumn{2}{|c|}{ No. of patients } & \multicolumn{2}{|c|}{ Gender (M/F) } & \multicolumn{2}{|c|}{ Mean age (years) } & \multicolumn{2}{|c|}{ Mean BMI $\left(\mathrm{kg} / \mathrm{m}^{2}\right)$} \\
\hline & Lap & Open & Lap & Open & Lap & Open & Lap & Open \\
\hline noRCT & 418 & 452 & $257 / 161$ & $266 / 186$ & 61.1 & 60.4 & 24.9 & 25.9 \\
\hline $\mathrm{RCT}$ & 404 & 410 & $249 / 155$ & $247 / 163$ & 58.2 & 58.3 & 24.1 & 24.1 \\
\hline Overall & 822 & 862 & $506 / 316$ & $513 / 349$ & 59.7 & 59.4 & 24.6 & 25.2 \\
\hline
\end{tabular}

BMI, body mass index; Lap, laparoscopic; ND, no data available; noRCT, prospective controlled clinical trial; Open, laparotomic; RCT, randomized controlled trial.

Table 3. Comparison of tumour location, cancer stage, neoadjuvant therapy, and protective ileostomy

\begin{tabular}{|c|c|c|c|c|c|c|c|c|c|c|c|c|}
\hline & \multicolumn{2}{|c|}{$\begin{array}{l}\text { No. of } \\
\text { patients }\end{array}$} & \multicolumn{2}{|c|}{$\begin{array}{l}\text { Mean distance } \\
\text { from the anal } \\
\text { verge }(\mathrm{cm})\end{array}$} & \multicolumn{2}{|c|}{$\begin{array}{l}\text { Tumour } \\
\text { stage } \mathrm{T} 0-\mathrm{T}_{2}^{\mathrm{a}}\end{array}$} & \multicolumn{2}{|c|}{$\begin{array}{l}\text { Tumour } \\
\text { stage } \mathrm{T} 3-\mathrm{T} 4^{\mathrm{a}}\end{array}$} & \multicolumn{2}{|c|}{$\begin{array}{l}\text { Neoadjuvant } \\
\text { therapy }\end{array}$} & \multicolumn{2}{|c|}{$\begin{array}{l}\text { Protective } \\
\text { ileostomy }(\%)^{\mathrm{b}}\end{array}$} \\
\hline & Lap & Open & Lap & Open & Lap & Open & Lap & Open & Lap & Open & Lap & Open \\
\hline noRCT & 418 & 452 & 6.1 & 5.4 & $171 / 332$ & $187 / 352$ & $161 / 332$ & $165 / 352$ & $224 / 275$ & $236 / 300$ & 48.0 & 56.0 \\
\hline $\mathrm{RCT}$ & 404 & 410 & 5.6 & 5.7 & $164 / 322$ & $141 / 321$ & $158 / 322$ & $180 / 321$ & $243 / 322$ & $247 / 321$ & 60.0 & 52.2 \\
\hline Overall & 822 & 862 & 5.8 & 5.5 & $335 / 654$ & $328 / 673$ & $319 / 654$ & $345 / 673$ & $467 / 597$ & $483 / 621$ & 54.6 & 54.3 \\
\hline
\end{tabular}

${ }^{\mathrm{a}}$ Number of T0-T2 and T3-T4 are not equal to total number since data was not available in all studies.

${ }^{b}$ Percentages of protective ileostomy are calculated, when available, on the number of patients undergoing a surgical procedure involving a bowel anastomosis.

Table 4. Quality assessment of the randomized controlled studies included, based on the Cochrane Collaboration's tool for assessing risk of bias

\begin{tabular}{|c|c|c|c|c|c|c|}
\hline Publication & $\begin{array}{l}\text { Random } \\
\text { sequence } \\
\text { generation }\end{array}$ & $\begin{array}{l}\text { Allocation } \\
\text { concealment }\end{array}$ & $\begin{array}{l}\text { Blinding of } \\
\text { participants, } \\
\text { personnel, } \\
\text { and outcome }\end{array}$ & $\begin{array}{l}\text { Incomplete } \\
\text { outcome } \\
\text { data }\end{array}$ & $\begin{array}{l}\text { Selective } \\
\text { outcome } \\
\text { reporting }\end{array}$ & $\begin{array}{l}\text { Other source } \\
\text { of bias }\end{array}$ \\
\hline Zhou et al. $(2004)^{12}$ & No & No & Unclear & Unclear & $\mathrm{No}^{\mathrm{a}}$ & Yes \\
\hline $\mathrm{Ng}$ et al. $(2008)^{17}$ & Yes $^{b}$ & Yes $^{c}$ & Unclear & Yes & Yes & Yes \\
\hline Lujan et al. $(2009)^{14}$ & Yes $^{b}$ & Yes $^{c}$ & Unclear & Yes & Yes & Yes \\
\hline Kang et al. $(2010)^{15}$ & Yes $^{\mathrm{b}}$ & Yes $^{c}$ & $Y_{e s}^{d}$ & Yes & Yes & Yes \\
\hline
\end{tabular}

In all cases, 'Yes' indicates a low risk of bias, 'No' indicates high risk of bias, and 'Unclear' indicates unclear or unknown risk of bias.

an Zhou (2004), no clear follow-up data are provided and no comparison between groups with regard to follow-up length is available.

${ }^{b}$ In Ng (2008), Lujan (2009), and Kang (2010), randomization sequence was generated by a computer program.

'In Kang (2010), allocation concealment was done by telephone by the trial coordinator; in Lujan (2009) by means of sealed envelopes; in Ng (2008) by an independent operating theatre coordinator.

${ }^{d}$ In Kang (2010), pathologists who examined the resected specimen were blinded as to allocation of patients.

intake recovery, blood transfusions, incidence of abscesses, incidence of wound complications, incidence of anastomotic leakages, incidence of re-intervention, and length of hospital stay.

Surgical complications, as reported in 10 studies, were significantly less frequent in the laparoscopic vs. the open group (13.5 vs. $17.5 \%$ ); the overall RR was 0.78 (95\% CI $0.62-0.97, p=0.027$; Figure 5), with no differences between RCT vs. noRCT subgroups (RR 0.65 vs. $0.86, p=0.247$ ).

Patients with medical complications, as reported in nine studies, were $18.5 \%$ in the laparoscopic group and $22.0 \%$ in the open surgery arm; the overall RR was 0.85 (95\% CI $0.70-1.04, p=0.114$; Figure 6), again with no differences between RCTs and noRCTs (RR 0.95 vs. $0.73, p=0.201)$. 
Table 5. Quality assessment of the included non-randomized controlled studies based on the Newcastle-Ottawa scale

\begin{tabular}{|c|c|c|c|c|c|c|c|c|}
\hline & \multicolumn{3}{|c|}{ Selections } & \multicolumn{2}{|c|}{ Comparability } & \multicolumn{2}{|c|}{ Outcome assessment } & \multirow[b]{2}{*}{ Scor } \\
\hline & 1 & 2 & 3 & 4 & 5 & 6 & 7 & \\
\hline Leung et al. $(2000)^{16}$ & * & - & - & * & $\star \star$ & - & * & 5 \\
\hline Hu et al. $(2003)^{20}$ & * & * & * & * & ** & * & * & 8 \\
\hline Breukink et al. $(2005)^{21}$ & * & * & * & * & $\star *$ & * & * & 8 \\
\hline Morino et al. $(2005)^{13}$ & * & * & * & ** & * & * & * & 8 \\
\hline Staudacher et al. $(2007)^{18}$ & * & * & * & ** & $\star \star$ & * & * & 9 \\
\hline Baik et al. $(2011)^{19}$ & * & * & * & ** & ** & * & * & 9 \\
\hline Seshadri et al. $(2012)^{22}$ & * & * & * & ** & ** & * & - & 8 \\
\hline
\end{tabular}

Selections: 1, Assignment for treatment (if yes, one point); 2, How representative was the laparoscopic group in comparison to the general population undergoing rectal resections (if yes, one point; no points if the patients were selected or selection of group was not described); 3, How representative was the open group in comparison to the general population undergoing rectal resections (if yes, one point; no points if the patients were selected or selection of group was not described).

Comparability: 4, Group comparable for age, gender, and American Society Anestesiologists (if yes, two points; one point if one of these three characteristics was not reported even if there were no other differences between the two groups and other characteristics had been controlled for; no points were assigned if the two groups differed); 5, Group comparable for neoadjuvant/adjuvant therapy, tumour location, stage, and procedure (if yes, two points; one point if one of these four characteristics was not reported even if there were no other differences between the two groups and other characteristics had been controlled for; no points were assigned if the two groups differed).

Outcome assessment: 6 , Clearly defined outcome of interest (if yes, one point for information ascertained by medical records or interview; no points if this information was not reported); 7, Follow-up equal between the two groups (if yes, one point; no points if follow-up not reported).

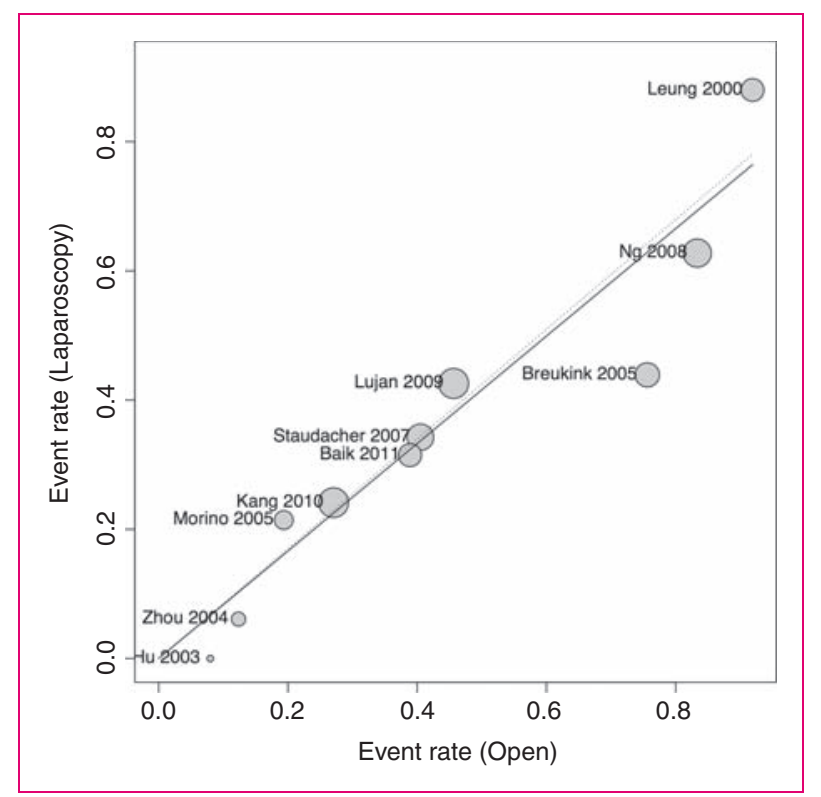

Figure 2. L'Abbé plot for all trials on mortality outcome to investigate potential sources of heterogeneity. Event rate plotted on vertical axis in for laparoscopy group and on horizontal axis for open group; size of circle proportional to number of patients enrolled; solid line represents the overall relative risk line, indicating estimation of relative risk by pooling results of all studies.

All but one study ${ }^{12}$ provided conversion to open surgery rate. Overall, 61 laparoscopic cases out of 740 were converted to laparotomy $(8.2 \%): 4.7 \%(15 / 322)$ in the RCT studies and $11.0 \%(46 / 418)$ in the noRCT studies.
Conversion rates ranged between $1.2 \%{ }^{15}$ and $9.8 \%{ }^{17}$ in the RCT studies, and between $0 \%{ }^{20}$ and $18.4 \%{ }^{13}$ in the noRCT studies. In the RCT studies, reported conversion rates showed a time trend, which was not apparent in the noRCTs (Table 1).

The weighted mean operative time, as reported in 10 studies, was significantly longer for laparoscopic surgery (216 and 179 minutes, respectively); the overall mean difference (MD) was 36.4 minutes (95\% CI 25.1-47.6, $p<0.001$; Figure 7), with no notable MDs between RCTs and noRCTs (32.4 vs. 39.4 minutes, $p=0.557)$, but with considerable heterogeneity $\left(I^{2} 83.4 \%\right)$.

The weighted mean blood loss, as reported in eight studies, was almost halved in the laparoscopic group (226 vs. $412 \mathrm{ml}$ ); the overall $\mathrm{MD}$ was $-138 \mathrm{ml}(95 \%$ CI -195 to $-81, p<0.001$; Figure 8 ), with borderline subgroup differences (MD -83 vs. $-181, p=0.056$ ) and consistent heterogeneity $\left(I^{2} 83.4 \%\right)$.

The overall incidence of intra-operative injuries, as reported in six studies, was $1.4 \%$ in both laparoscopic and open surgery patients; the overall RR was 1.10 (95\% CI 0.41-2.91, $p=0.851$; Figure 9), with no differences between RCTs and noRCTs (RR 1.65 vs. 0.74 $p=0.428$ ).

The weighted mean time for bowel movement recovery, as reported in six studies, was significantly shorter in the laparoscopic group (3.5 vs. 4.7 days); the overall MD was -1.3 days $(95 \% \mathrm{CI}-1.8$ to $-0.9, p<0.001$; Figure 10), with no significant MD between RCTs and noRCTs (MD -1.2 vs. $-1.3, p=0.827$ ) but in the presence of extreme heterogeneity $\left(I^{2} 83.9 \%\right)$. 


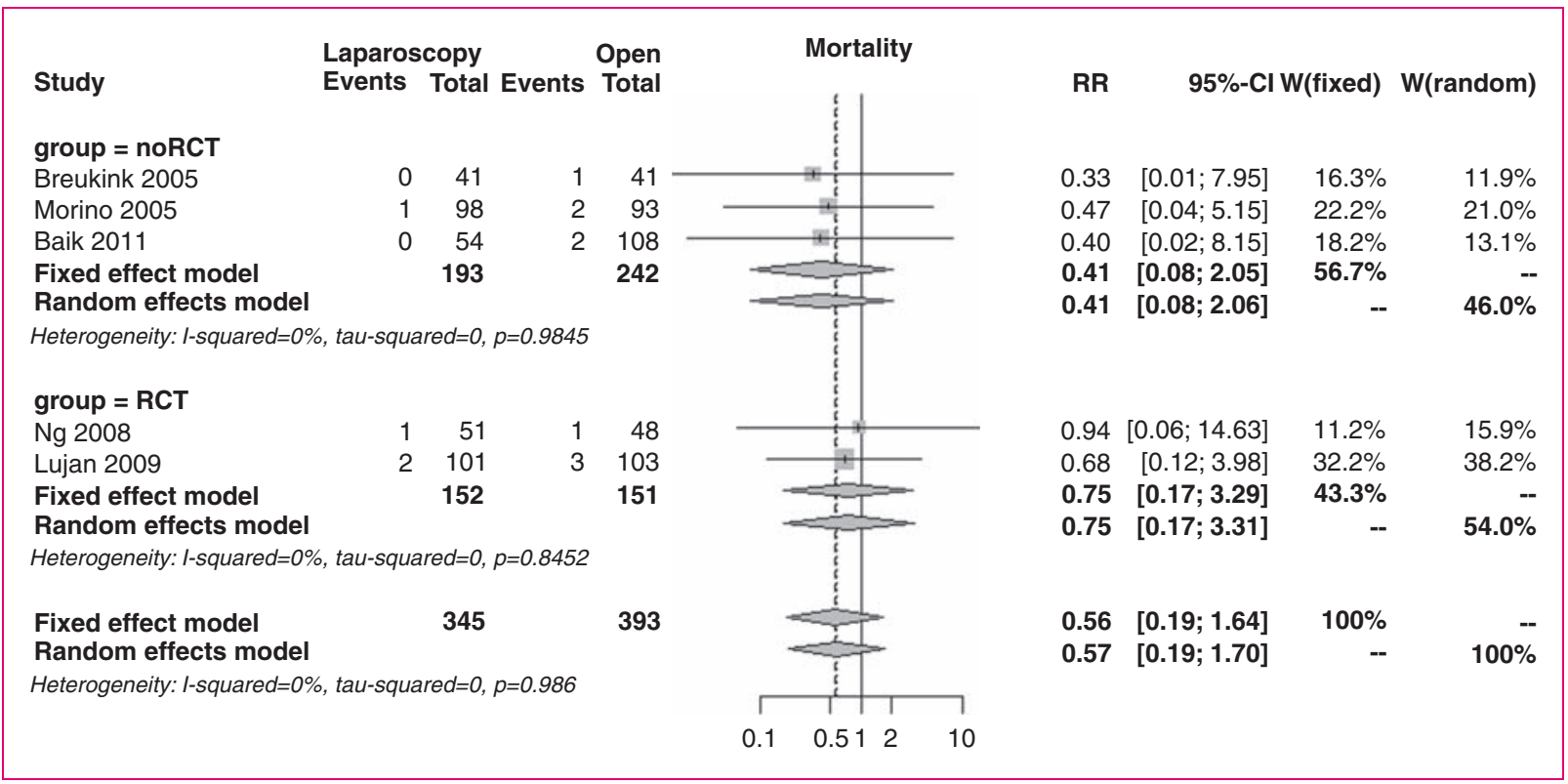

Figure 3. Forest plot for 30-day mortality.

$\mathrm{Cl}$, confidence interval; RR, relative risk; W, weight of single study.

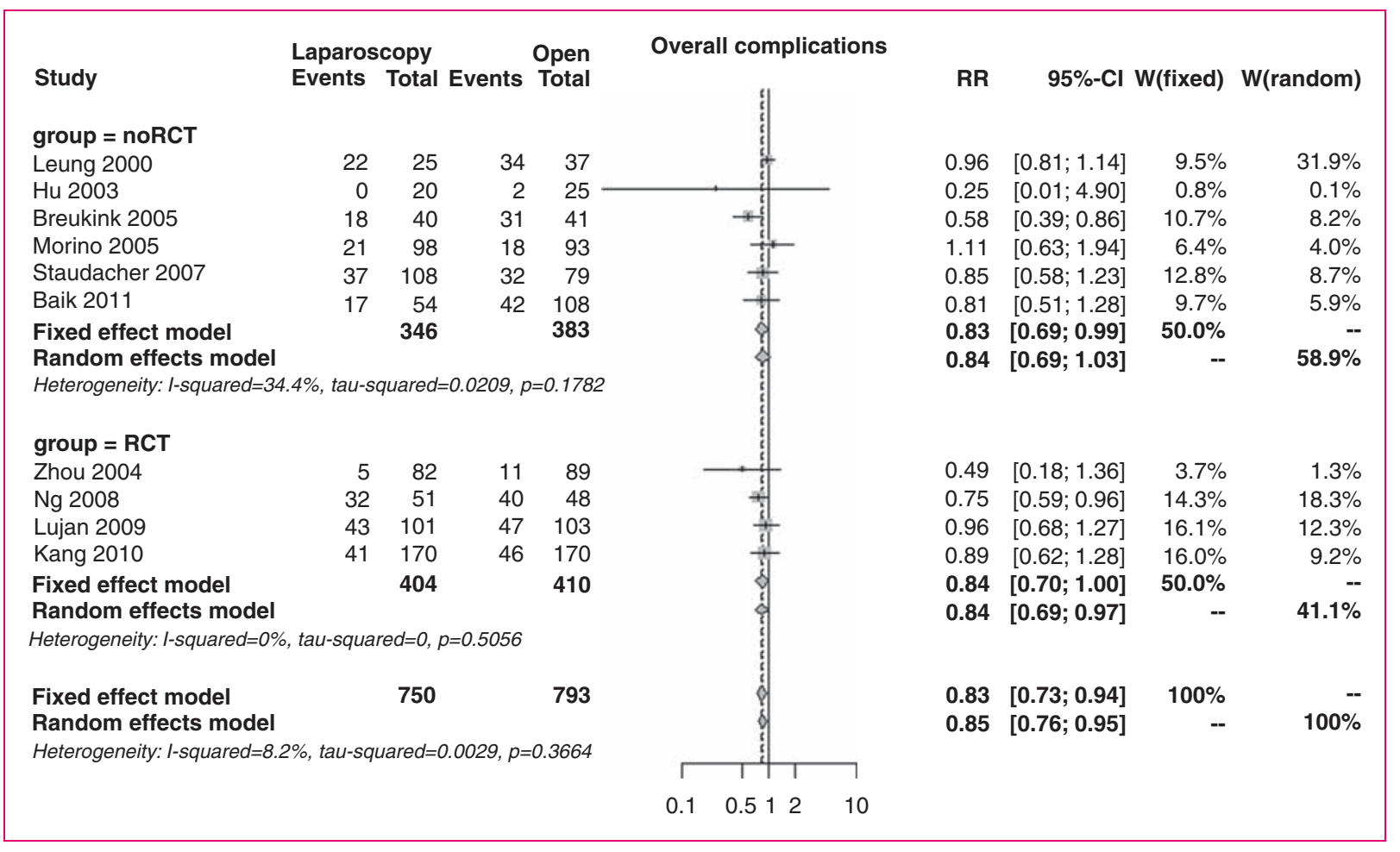

Figure 4. Forest plot for overall 30-day morbidity.

$\mathrm{Cl}$, confidence interval; RR, relative risk; $\mathrm{W}$, weight of single study.

The weighted mean food intake recovery, as reported in nine studies, occurred after 4.0 days in the laparoscopic group and 4.8 days in the open surgery group, significantly favouring the former; the overall
MD was -0.9 days $(95 \%$ CI -1.4 to $-0.4, p<0.001$; Figure 11), showing a significant MD between RCTs and noRCTs (MD -0.3 vs. $-1.0, p=0.031$ ) and extreme heterogeneity $\left(I^{2} 75.9 \%\right)$. 


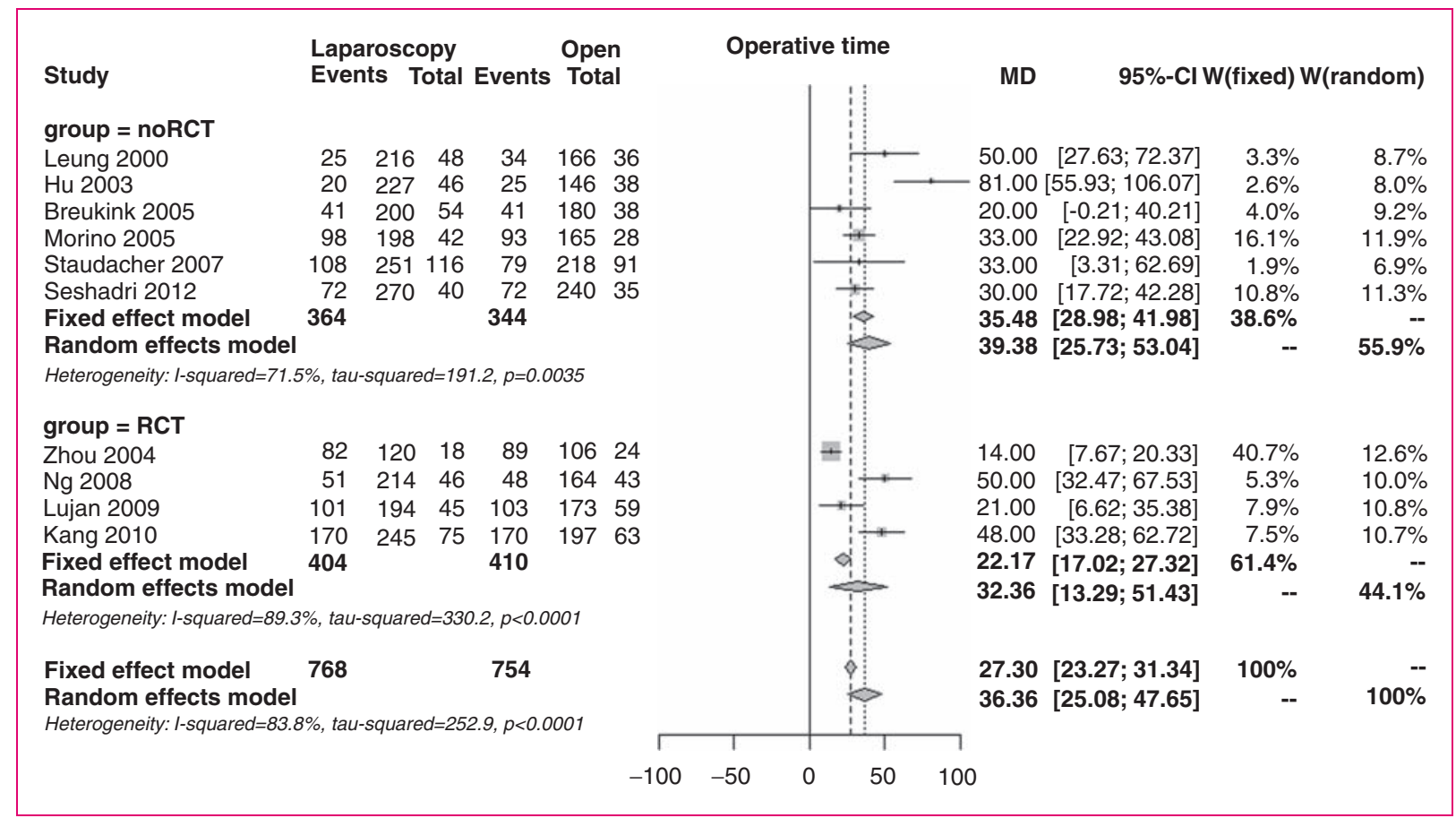

Figure 7. Forest plot for mean operative time.

$\mathrm{Cl}$, confidence interval; MD, mean difference; $\mathrm{W}$, weight of single study.

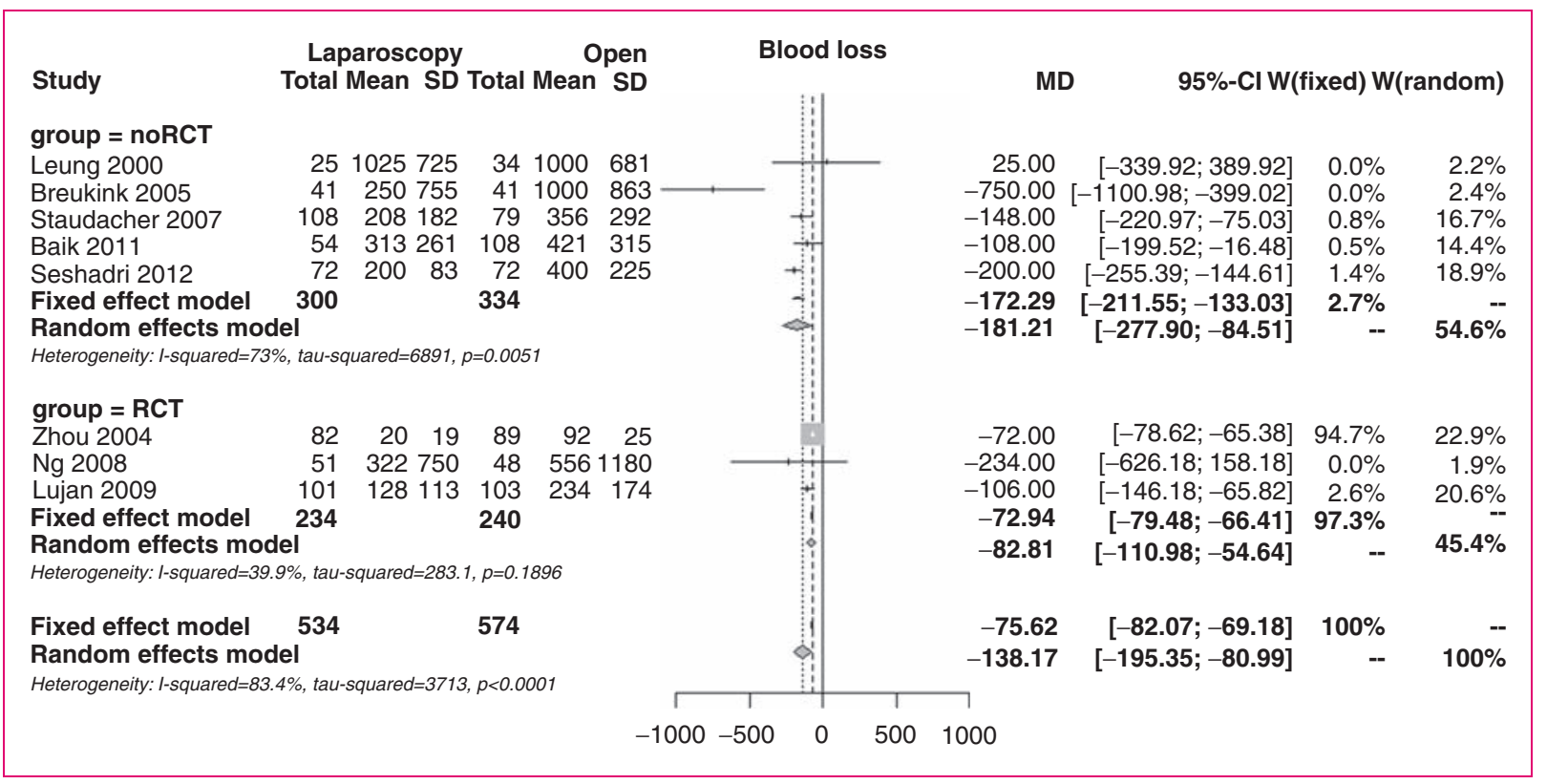

Figure 8. Forest plot for mean blood loss.

$\mathrm{Cl}$, confidence interval; $\mathrm{MD}$, mean difference; $\mathrm{W}$, weight of single study.

The percentage of laparoscopic patients requiring blood transfusions, as reported in three studies, was significantly lower than that for open surgery patients $(4.5$ vs. $7.0 \%)$; the overall RR was 0.55 (95\% CI $0.31-0.98$, $p=0.041$; Figure 12), in the absence of subgroup differences (RR 0.33 vs. $0.57, p=0.749$ ).

Abscesses, as reported in seven studies, were observed in $1.8 \%$ of patients in the laparoscopic 


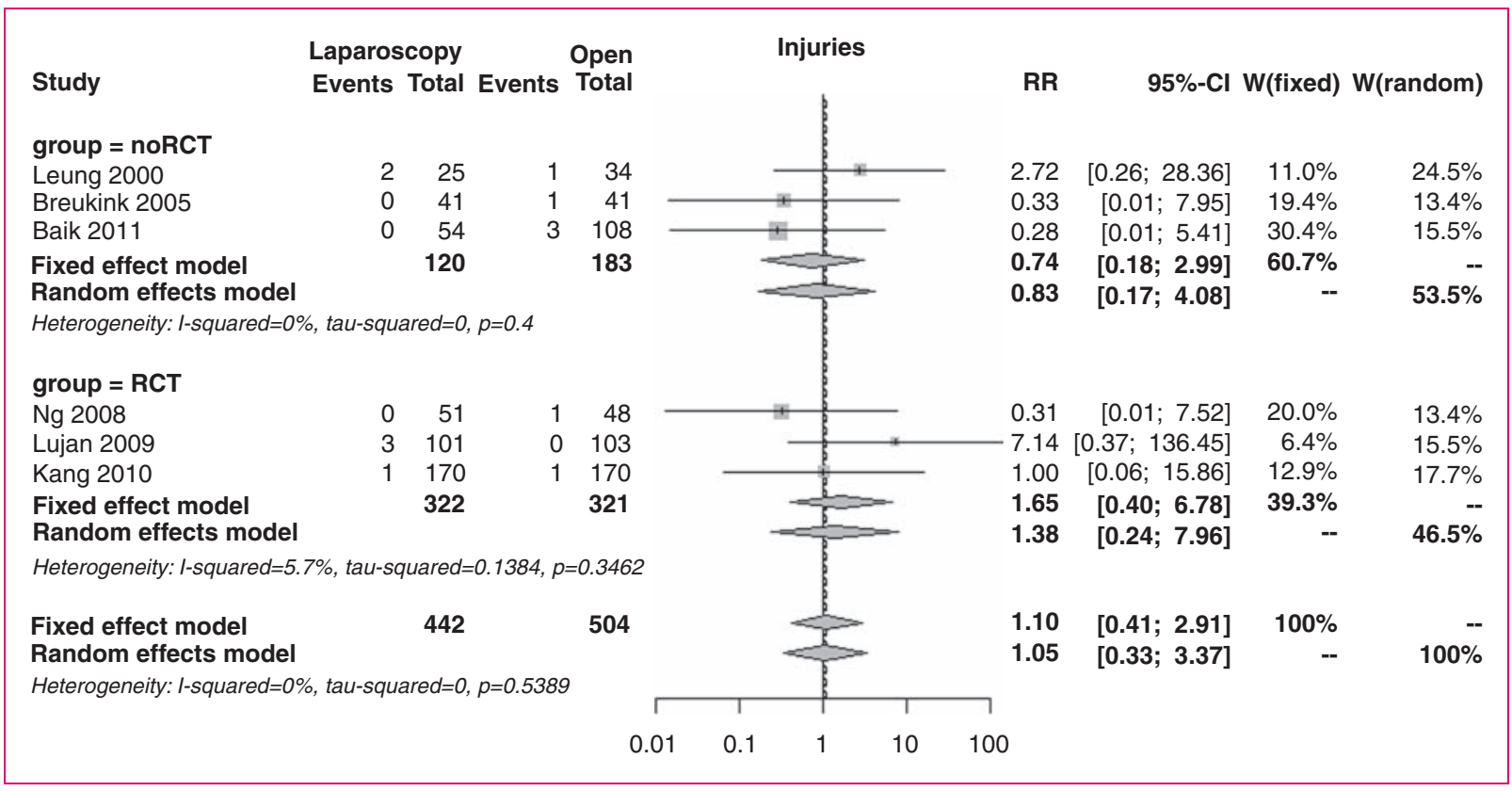

Figure 9. Forest plot for incidence of intra-operative injuries.

$\mathrm{Cl}$, confidence interval; RR, relative risk; W, weight of single study.

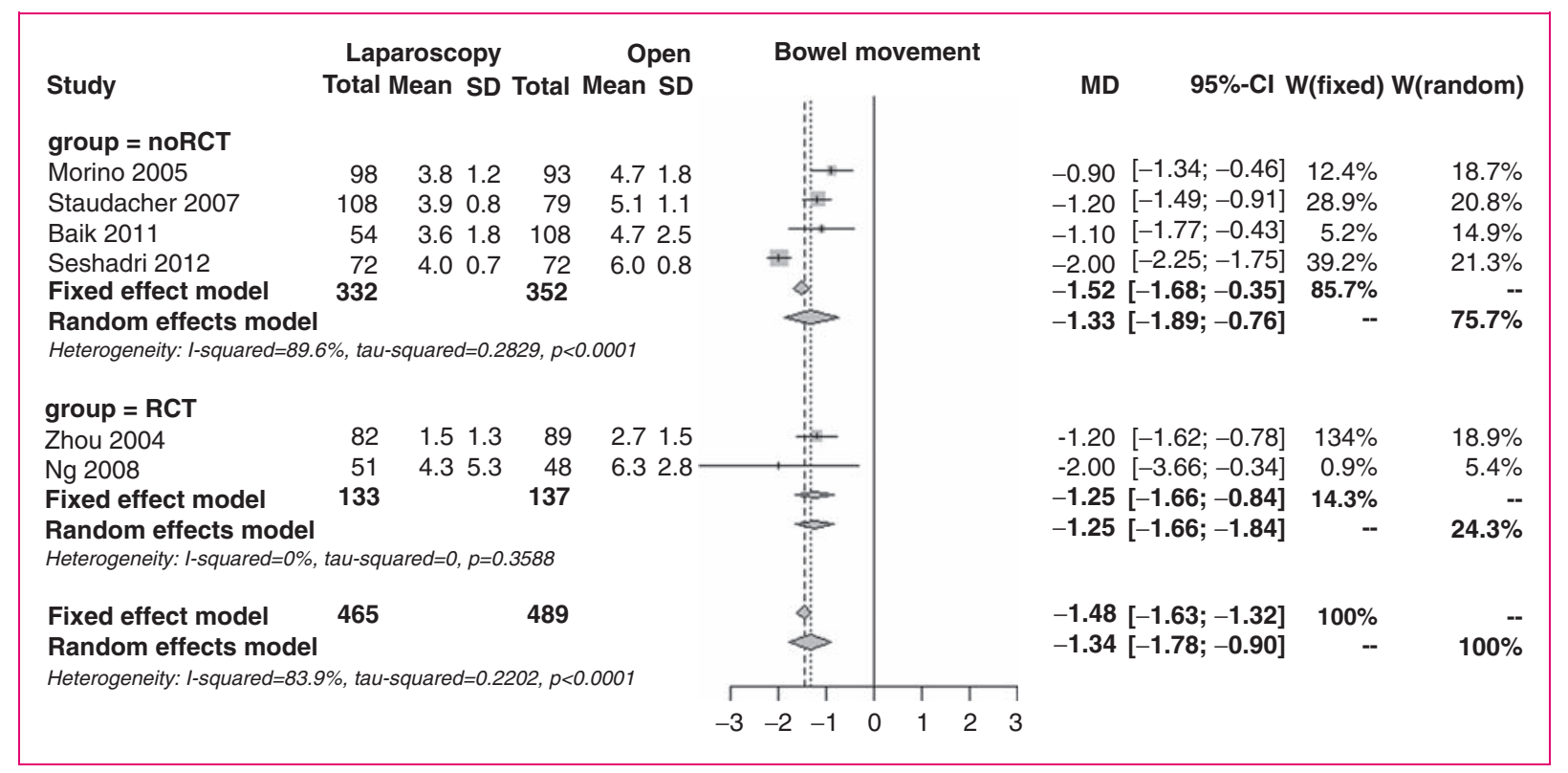

Figure 10. Forest plot for bowel movement recovery.

$\mathrm{Cl}$, confidence interval; $\mathrm{MD}$, mean difference; W, weight of single study.

group and $1.9 \%$ of patients in the open group; the overall RR was 1.08 (95\% CI $0.50-2.36, p=0.837$; Figure 13), showing no subgroup differences (RR 1.00 vs. $1.14, p=0.871)$.

On the other hand, wound complications, as reported in 10 studies, were described for $6.9 \%$ laparoscopic and $11.1 \%$ open patients; the overall $\mathrm{RR}$ was $0.63 \quad(95 \% \quad \mathrm{CI} \quad 0.46-0.86, \quad p=0.004$; Figure 14), with no subgroup differences (RR 0.57 vs. $0.66, p=0.646$ ).

Anastomotic leakages, as reported in eight studies, occurred in $6.9 \%$ of laparoscopic patients and $6.3 \%$ 


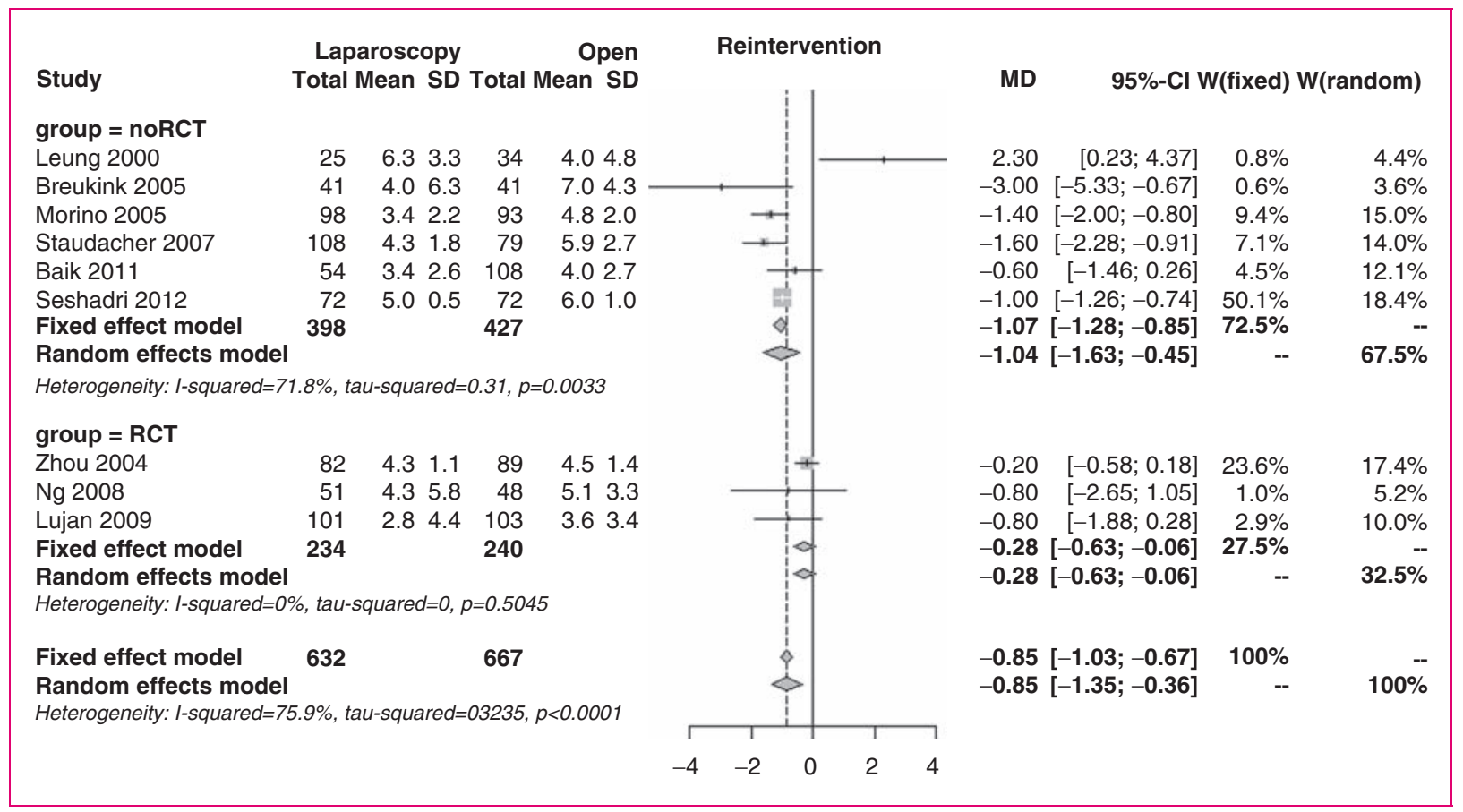

Figure 11. Forest plot for food intake recovery.

$\mathrm{Cl}$, confidence interval; MD, mean difference; W, weight of single study.

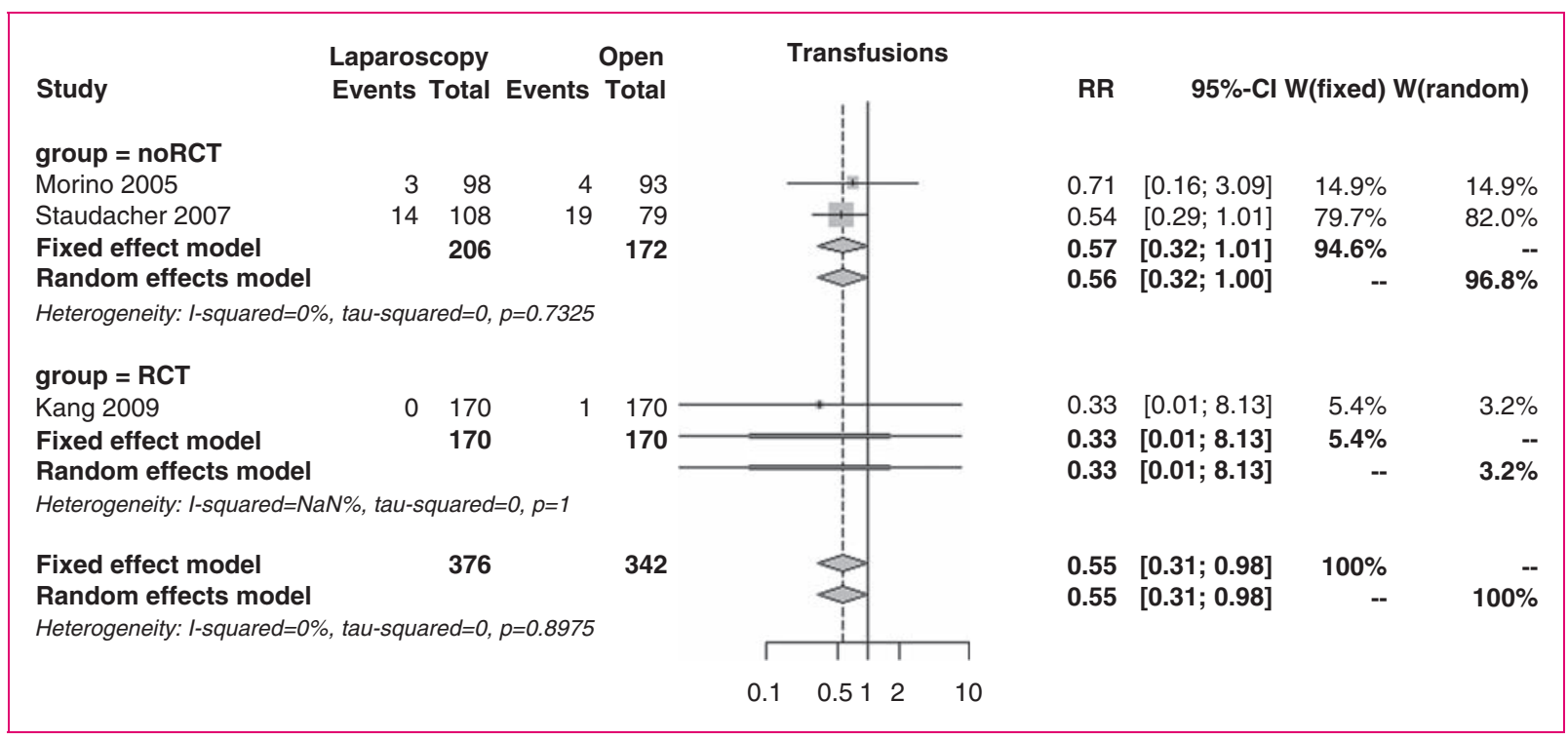

Figure 12. Forest plot for incidence of blood transfusion.

$\mathrm{Cl}$, confidence interval; RR, relative risk; $\mathrm{W}$, weight of single study.

of open patients. The overall RR was 1.05 (95\% CI $0.68-1.61, p=0.833$; Figure 15), with no differences between RCTs and noRCTs (RR 0.66 vs. 1.26, $p=0.192)$.

Patients who needed surgical re-intervention within the first 30 postoperative days, as reported in six studies, were $5.3 \%$ in the laparoscopic group and $6.9 \%$ in the open group; the overall RR was 0.75 $(95 \%$ CI $0.47-1.19, p=0.217$; Figure 16$)$, again with no subgroup differences (RR 0.71 vs. $0.78, p=0.838$ ).

The weighted mean duration for hospital stay, as reported in 10 studies, was clearly shorter in the 


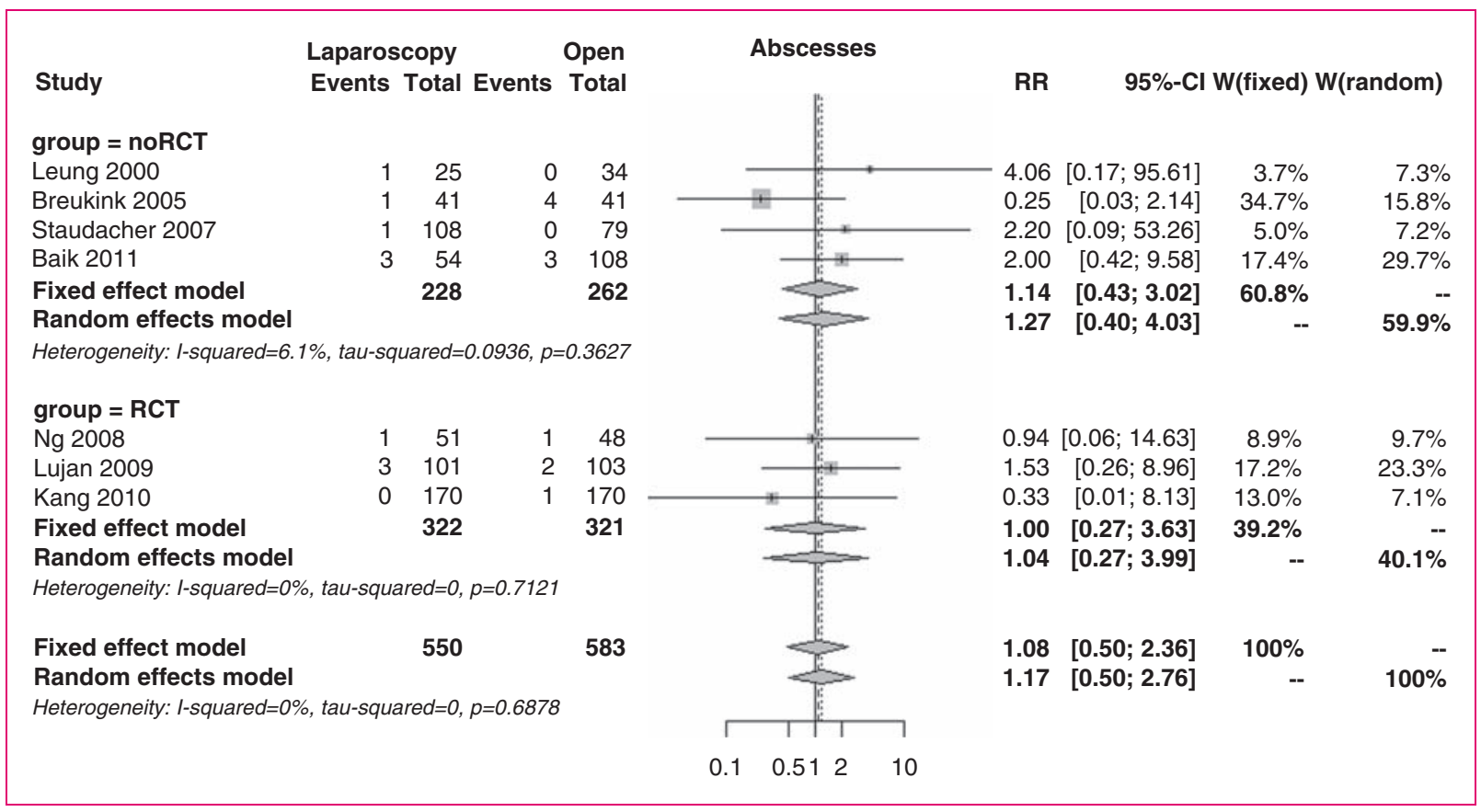

Figure 13. Forest plot for incidence of abdominal abscesses.

$\mathrm{Cl}$, confidence interval; RR, relative risk; $\mathrm{W}$, weight of single study.

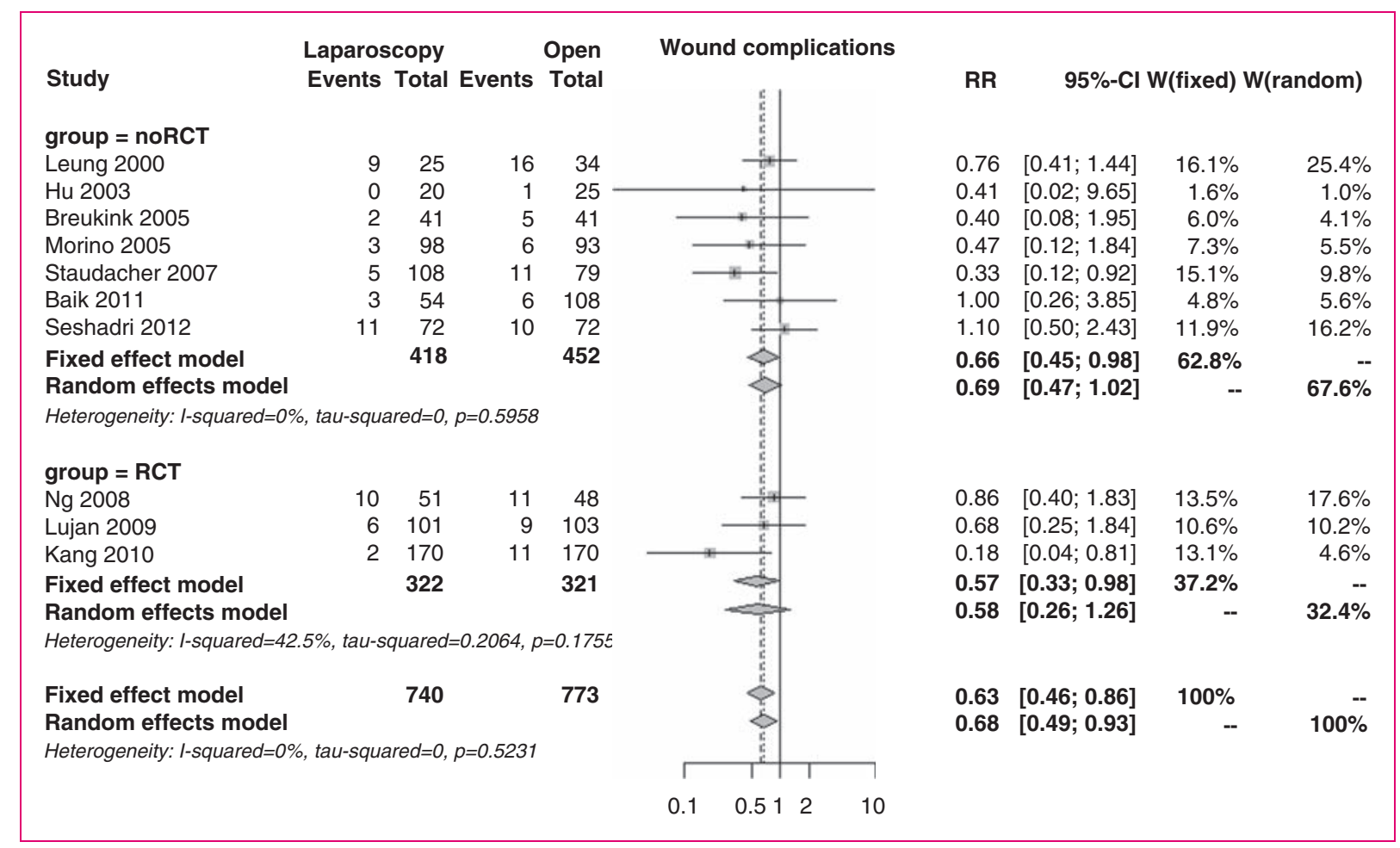

Figure 14. Forest plot for incidence of wound complications.

$\mathrm{Cl}$, confidence interval; RR, relative risk; W, weight of single study. 


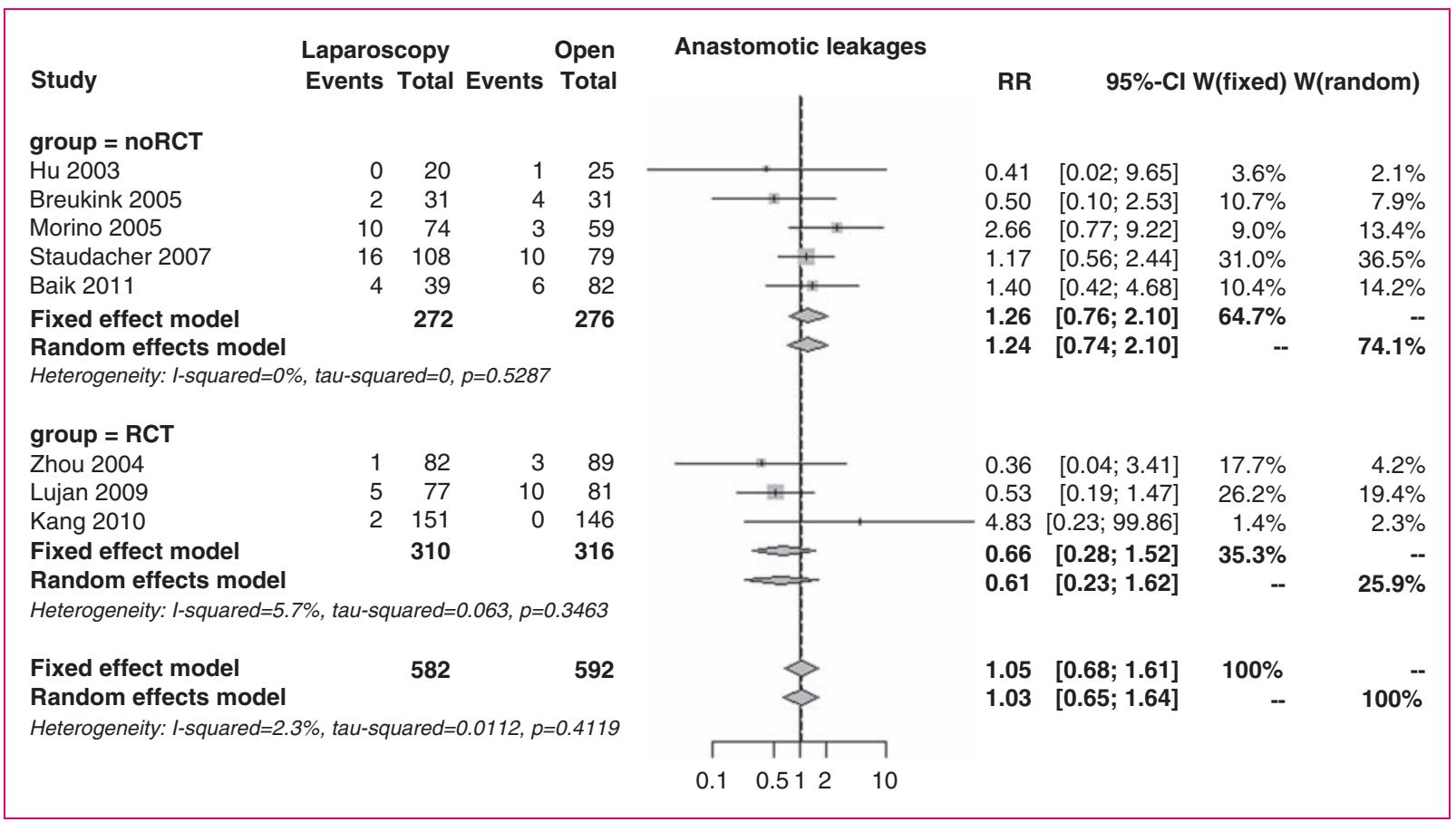

Figure 15. Forest plot for incidence of anastomotic leakage.

$\mathrm{Cl}$, confidence interval; RR, relative risk; $\mathrm{W}$, weight of single study.

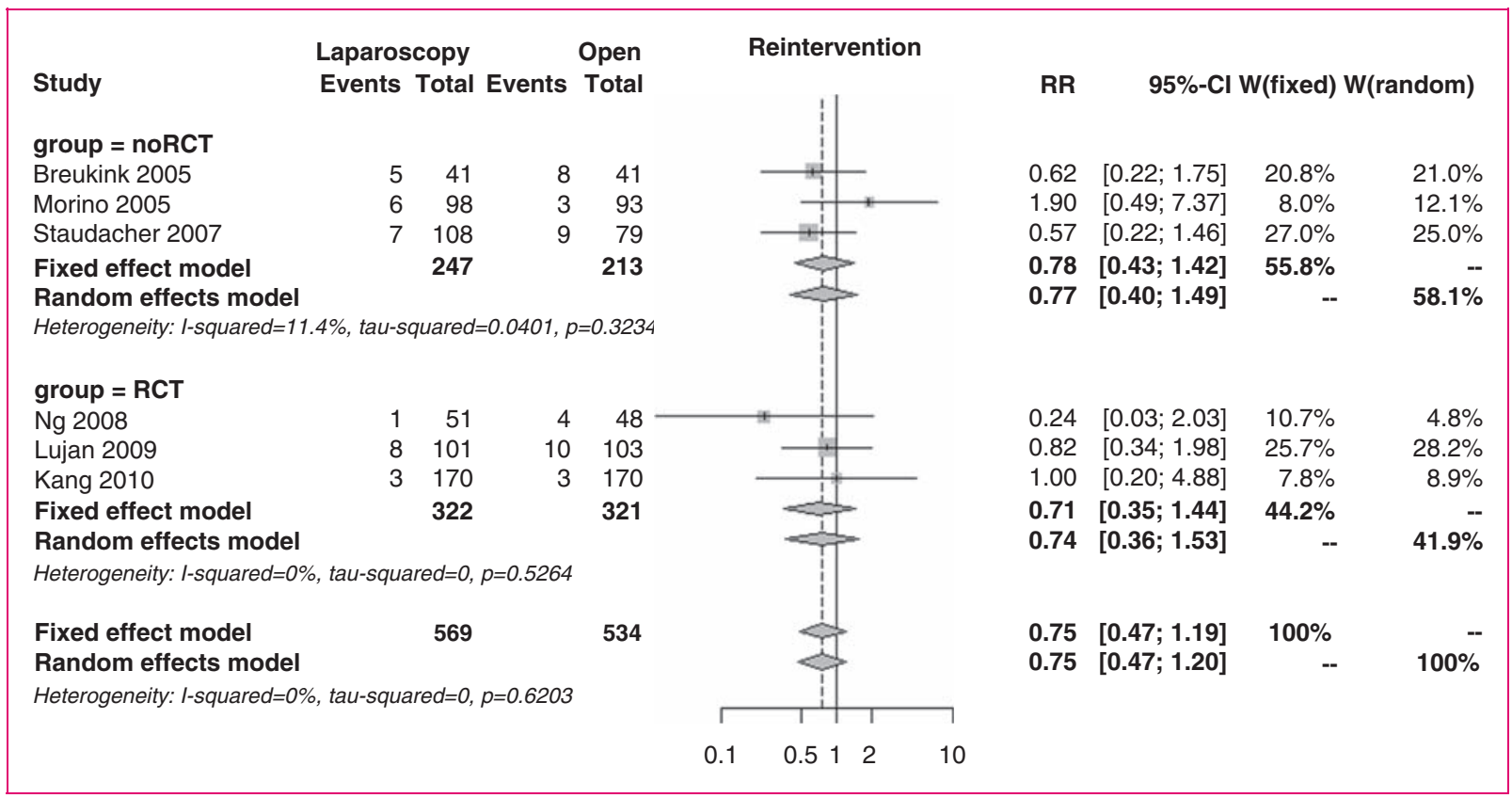

Figure 16. Forest plot for incidence of re-intervention.

$\mathrm{Cl}$, confidence interval; RR, relative risk; $\mathrm{W}$, weight of single study.

laparoscopy surgery patients (10.2 vs. 12.4 days); the overall MD was -2.2 days $(95 \%$ CI -3.7 to -0.7 , $p=0.005$; Figure 17), with no differences in the subgroup analysis (MD -2.7 vs. $-1.9, p=0.651$ ), but with extreme heterogeneity $\left(I^{2} 79.8 \%\right)$.

\section{Discussion}

According to European registries, the prevalence of rectal cancer exceeds 50 cases per 100,000 (women and men). It accounts for almost $40 \%$ of all colorectal 


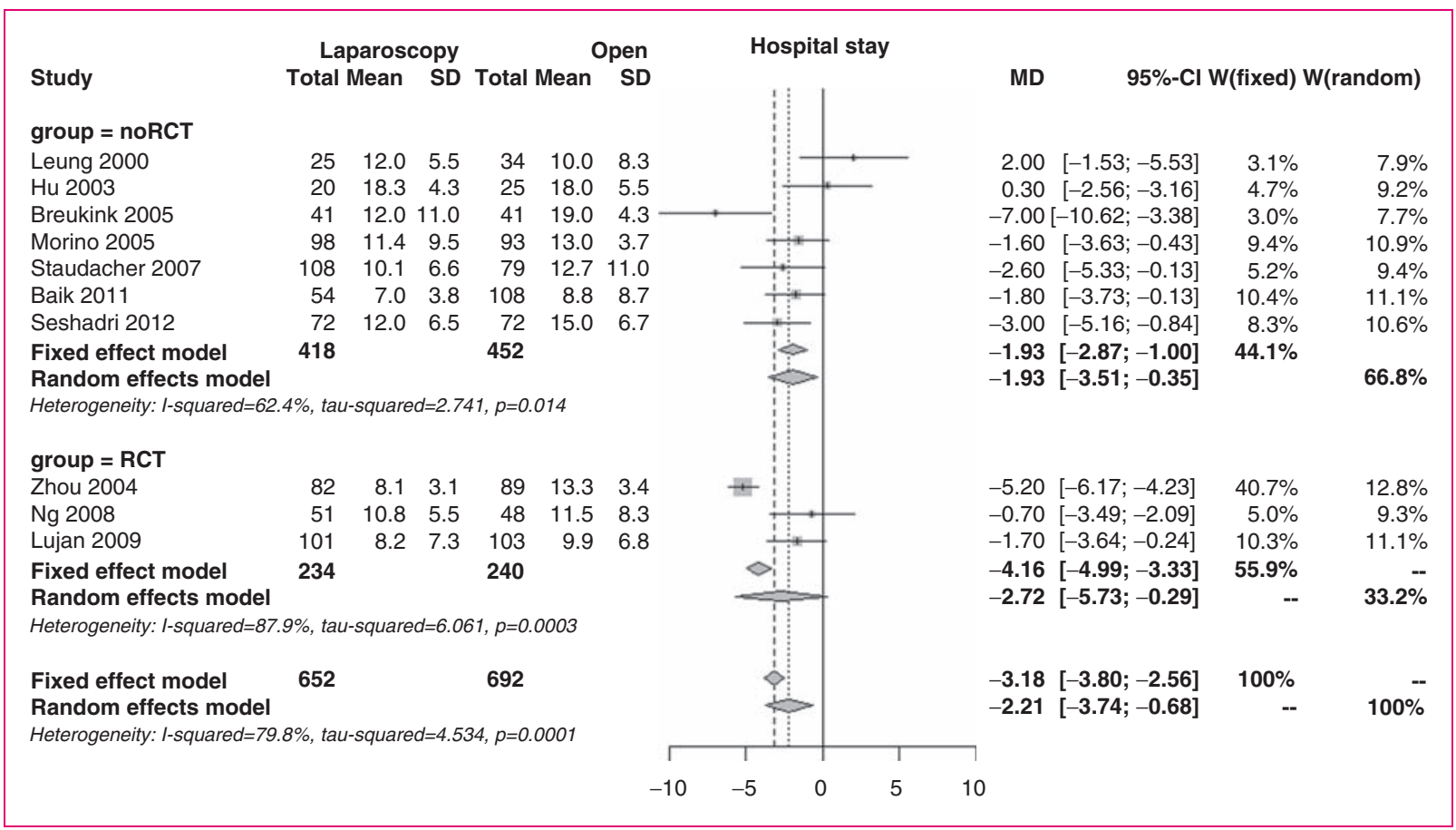

Figure 17. Forest plot for length of hospital stay.

$\mathrm{Cl}$, confidence interval; $\mathrm{MD}$, mean difference; $\mathrm{W}$, weight of single study.

cancer cases ${ }^{23,24}$ representing one of the leading causes of cancer mortality, in which local recurrence of rectal cancer plays a major role. For mid and low rectal cancers, total mesorectal excision remains the main-stay of therapy. The feasibility of laparoscopic resection of rectal cancer has been demonstrated for many years when performed by expert laparoscopists, but while the laparoscopic approach in colon cancer has been proved to be safe and feasible with equivalent longterm oncological outcome compared to open surgery, ${ }^{3-5}$ the safety of laparoscopic surgery for rectal cancer is still debated both for short-term and longterm outcomes.

While mid and long-term oncological results are awaited, the present study aimed to assess by means of a systematic review and meta-analysis, the shortterm safety of laparoscopic resection for extraperitoneal rectal cancer. Different meta-analyses have compared laparoscopic and open techniques for colorectal $^{25-29}$ and later for rectal cancers, ${ }^{30-33}$ although only including intra-peritoneal lesions. This is in fact the first meta-analysis that focuses only on extra-peritoneal rectal cancers. In this restricted field of mid and low rectal surgery, the issue of increased technical challenges arises.

Since 2000,11 studies ${ }^{12-22}$ have been published comparing laparoscopic and open rectal resection in terms of safety. We restricted the beginning of the analysis to the year 2000 in order to include studies performed with a relative experience of the technique, as it had already been proposed around 8 years previously. This was considered important in order to obtain results as homogeneous as possible. Although a meta-analysis of only RCT studies might be considered preferable, the risk of bias analysis and the heterogeneity test showed that extending the inclusion criteria to prospective non-randomized matched series would have allowed a consistent level of evidence to be maintained. The heterogeneity of results was null or kept within a reasonable range for most of the outcomes considered, in particular for the two primary ones, despite the fact that some of the study samples included in this analysis were relatively small and that none of the studies included had made an estimate of what sample size was needed to detect any differences between laparoscopic and open surgery based on a well-defined primary outcome. The sensitivity analyses showed that no study played an influential role on RR in the whole time period. Where data were available, stage of cancer disease, neoadjuvant chemoradiotherapy, protective ileostomy rates, and type of surgery (partial or total mesorectal excision or abdominoperineal resection) were all variables considered in the comparative analysis between open and laparoscopic groups. The quality assessment for both RCT and noRCT studies as measured by the Cochrane Collaboration's tool for assessing risk of bias and the Newcastle-Ottawa scale was interestingly high. 
An important aspect of the present analysis is that all studies were performed at specialized centres by highly experienced surgeons, and that patients were rigorously selected, particularly those staged $\mathrm{T} 4$ by TNM stage who were excluded in all but two studies.

In the light of the methodology of the present study, the results obtained appear highly significant. The main result of the meta-analysis was that the incidence of overall morbidity at 30 days showed a significant reduction in the laparoscopic group compared to open surgery with an RR of 0.83 . Furthermore the mortality analysis showed a trend in favour of laparoscopy, although it may not have reached statistical significance due to the relative rarity of the event. The subgroup analysis confirmed that surgical complications are also significantly lower in the laparoscopic group, while medical complications showed a consistent trend in favour of laparoscopy although with no statistical significance. Apart from the operative time, which was significantly in favour of open surgery, the analysis of all the studies included showed a clear advantage for laparoscopy also in the specific analysis of other comparative outcomes. Blood loss, time for bowel movement recovery, food intake recovery, need for blood transfusion, wound complications, and duration of hospital stay were all significantly in favour of laparoscopy, while no significant difference was observed in terms of anastomotic leakages, intraoperative injuries, abscess formation, and the need for surgical re-intervention at 30 days.

While most of the above-mentioned results were expected, as they confirmed the well-known advantages of minimally invasive techniques shown in other surgical procedures, the absence of any difference in anastomotic leakage rates was particularly striking. In fact, in the past few years, concern has been expressed about the increase in anastomotic leakage risk associated with laparoscopy. This risk was accounted for by the difficult access of laparoscopic linear staplers to the distal rectum in a narrow pelvis, the oblique transection from right to left or from anterior to posterior (depending on the position of the trocar used for the stapler), and the difficulty of cephalad traction on the rectum. This had led the EAES Consensus panel of experts to affirm that 'a cautionary note should be commented in relation to the anastomotic leak rate, in relation to the difficulty observed for low rectal transection in the obese or in those with a narrow pelvis space'. ${ }^{34}$ In recent years, the advent of new technologies, such as the ultrasonic scalpel and articulated stapler, and the increase in surgical experience has resulted in a progressive optimization of the technique which has recently led to an equivalence in leakage rates and a lower incidence of surgical complications with the laparoscopic approach.
Only the lack of sufficient data referring to sexual and urinary dysfunctions, postoperative quality of life and R0 achievement, and sphincter preservation rates prevented further analyses which would also undoubtedly have proved interesting from being performed.

The results obtained should in any case be interpreted with caution as the present analysis shows certain limitations. Despite the high quality assessment for low risk of bias, most of the studies did not have shortterm complications as primary outcome, while others lacked important data with regard to secondary outcomes.

In spite of the above-mentioned limitations, it can be concluded that, based on the evidence of both randomized and prospective matched series, laparoscopic resection appears to have clinically measurable shortterm advantages in patients with primary resectable extraperitoneal rectal cancer. Although technically demanding, laparoscopic rectal resection for extraperitoneal cancer in selected patients can be considered safe and guarantees faster recovery; it is therefore to be recommended under optimal conditions.

\section{Funding}

The work described in this paper was funded in part by the European Commission within the STIFF-FLOP FP7 European project FP7/ICT-2011-7-287728.

\section{Conflict of interest}

They authors have no conflict of interests to declare, including financial interests and relationships and affiliations relevant to the subject of their manuscript.

\section{References}

1. Jacobs M, Verdeja JC and Goldstein HS. Minimally invasive colon resection (laparoscopic colectomy). Surg Laparosc Endosc 1991; 1: 144-150.

2. Lacy AM, Garcia-Valdecasas JC, Delgado S, et al. Laparoscopy-assisted colectomy versus open colectomy for treatment of non-metastatic colon cancer: a randomised trial. Lancet 2002; 359: 2224-2229.

3. Guillou PJ, Quirke P, Thorpe H, et al. Short-term endpoints of conventional versus laparoscopic-assisted surgery in patients with colorectal cancer (MRC CLASICC trial): multicentre, randomised controlled trial. Lancet 2005; 365: 1718-1726.

4. Clinical Outcomes of Surgical Therapy Study Group. A comparison of laparoscopically assisted and open colectomy for colon cancer. $N$ Engl J Med 2004; 350: 2050-2059.

5. Veldkamp R, Kuhry E, Hop WC, et al.; Colon cancer Laparoscopic or Open Resection Study Group (COLOR). Laparoscopic surgery versus open surgery for colon cancer: short-term outcomes of a randomised trial. Lancet Oncol 2005; 6: 477-484. 
6. Heald RJ, Moran BJ, Ryall RD, et al. Rectal cancer: the Basingstoke experience of total mesorectal excision, 1978-1997. Arch Surg 1998; 133: 894-899.

7. Ries LA, Wingo PA, Miller DS, et al. The annual report to the nation on the status of cancer, 1973-1997, with a special section on colorectal cancer. Cancer 2000; 88: 2398-2424.

8. Lacy A. Colon cancer: laparoscopic resection. Ann Oncol 2005; 16(Suppl 2): ii88-92. Review.

9. Ortiz H, Armendariz P and Yarnoz C. Early postoperative feeding after elective colorectal surgery is not a benefit unique to laparoscopy-assisted procedures. Int $J$ Colorectal Dis 1996; 11: 246-249.

10. Liberati A, Altman DG, Tetzlaff J, et al. The PRISMA statement for reporting systematic reviews and meta-analyses of studies that evaluate health care interventions: explanation and elaboration. Ann Intern Med 2009; 151: 65-94.

11. Stroup DF, Berlin JA, Morton SC, et al. Meta-analysis of observational studies in epidemiology: a proposal for reporting. Meta-analysis Of Observational Studies in Epidemiology (MOOSE) group. JAMA 2000; 283: 2008-2012.

12. Zhou ZG, Hu M, Li Y, et al. Laparoscopic versus open total mesorectal excision with anal sphincter preservation for low rectal cancer. Surg Endosc 2004; 18: 1211-1215.

13. Morino M, Allaix ME, Giraudo G, et al. Laparoscopic versus open surgery for extraperitoneal rectal cancer: a prospective comparative study. Surg Endosc 2005; 19: 1460-1467.

14. Lujan J, Valero G, Hernandez Q, et al. Randomized clinical trial comparing laparoscopic and open surgery in patients with rectal cancer. Br J Surg 2009; 96: 982-989.

15. Kang SB, Park JW, Jeong SY, et al. Open versus laparoscopic surgery for mid or low rectal cancer after neoadjuvant chemoradiotherapy (COREAN trial): short-term outcomes of an open-label randomised controlled trial. Lancet Oncol 2010; 11: 637-645.

16. Leung KL, Kwok SP, Lau WY, et al. Laparoscopicassisted abdominoperineal resection for low rectal adenocarcinoma. Surg Endosc 2000; 14: 67-70.

17. Ng SS, Leung KL, Lee JF, et al. Laparoscopic-assisted versus open abdominoperineal resection for low rectal cancer: a prospective randomized trial. Ann Surg Oncol 2008; 15: 2418-2425. Erratum: Ann Surg Oncol 2009; 16: 229.

18. Staudacher C, Vignali A, Saverio DP, et al. Laparoscopic vs. open total mesorectal excision in unselected patients with rectal cancer: impact on early outcome. Dis Colon Rectum 2007; 50: 1324-1331.

19. Baik SH, Gincherman M, Mutch MG, et al. Laparoscopic vs open resection for patients with rectal cancer: comparison of perioperative outcomes and longterm survival. Dis Colon Rectum 2011; 54: 6-14.

20. Hu JK, Zhou ZG, Chen ZX, et al. Comparative evaluation of immune response after laparoscopical and open total mesorectal excisions with anal sphincter preservation in patients with rectal cancer. World $J$ Gastroenterol 2003; 9: 2690-2694.

21. Breukink SO, Pierie JP, Grond AJ, et al. Laparoscopic versus open total mesorectal excision: a case-control study. Int J Colorectal Dis 2005; 20: 428-433.

22. Seshadri RA, Srinivasan A, Tapkire R, et al. Laparoscopic versus open surgery for rectal cancer after neoadjuvant chemoradiation: a matched case-control study of short-term outcomes. Surg Endosc 2012; 26: 154-161.

23. GLOBOCAN IARC. GLOBOCAN 2008 Fast Stats. Available at: http://globocan.iarc.fr/factsheets/popula tions/factsheet.asp?uno=900\#BOTH $\quad(2011, \quad$ accessed Mar 2011).

24. Micheli A. Cancer prevalence in European registry areas. Ann Oncol 2002; 13: 840-865.

25. Li MZ, Xiao LB, Wu WH, et al. Meta-analysis of laparoscopic versus open colorectal surgery within fast-track perioperative care. Dis Colon Rectum 2012; 55: 821-827.

26. Kuhry E, Schwenk WF, Gaupset R, et al. Long-term results of laparoscopic colorectal cancer resection. Cochrane Database Syst Rev 2008; (2): CD003432.

27. Ohtani H, Tamamori Y, Arimoto Y, et al. A meta-analysis of the short- and long-term results of randomized controlled trials that compared laparoscopy-assisted and conventional open surgery for colorectal cancer. J Cancer 2011; 2: 425-434.

28. Sammour T, Kahokehr A, Srinivasa S, et al. Laparoscopic colorectal surgery is associated with a higher intraoperative complication rate than open surgery. Ann Surg 2011; 253: 35-43.

29. Ma Y, Yang Z, Qin H, et al. A meta-analysis of laparoscopy compared with open colorectal resection for colorectal cancer. Med Oncol 2011; 28: 925-933.

30. Huang MJ, Liang JL, Wang $\mathrm{H}$, et al. Laparoscopicassisted versus open surgery for rectal cancer: a metaanalysis of randomized controlled trials on oncologic adequacy of resection and long-term oncologic outcomes. Int J Colorectal Dis 2011; 26: 415-421.

31. Racheva $\mathrm{G}$ and Elmusharaf $\mathrm{H}$. A systematic review and meta-analysis of randomized and non-randomized studies comparing laparoscopic and open abdominoperineal resection for rectal cancer. Colorectal Dis 2012 (Epub ahead of print).

32. Trastulli S, Cirocchi R, Listorti C, et al. Laparoscopic vs open resection for rectal cancer: a meta-analysis of randomized clinical trials. Colorectal Dis 2012; 14: e277-e296.

33. Aziz O, Constantinides V, Tekkis PP, et al. Laparoscopic versus open surgery for rectal cancer: a meta-analysis. Ann Surg Oncol 2006; 13: 413-424.

34. Siegel R, Cuesta MA, Targarona E, et al.; European Association for Endoscopic Surgery (EAES). Laparoscopic extraperitoneal rectal cancer surgery: the clinical practice guidelines of the European Association for Endoscopic Surgery (EAES). Surg Endosc 2011; 25: 2423-2440. 